\title{
Biopower, racialization and new security technology
}

\author{
Mark Maguire* \\ Department of Anthropology, National University of Ireland, Maynooth \\ (Received 17 May 2010; final version received 24 January 2012)
}

\begin{abstract}
From fingerprinting in colonial contexts to scientific racism, and from face recognition pioneers to contemporary multi-modal surveillance, biometric security has long been connected to processes of racialization. Using both contemporary and historical examples, this article explores the rollout of biometric security, paying especial attention to how biometrics makes use of and relies upon racialized configurations of population. The article explores these connections and teases out the precise ways in which 'race' and racialization connect to the securitization of individual identities. This article also opens a space for a discussion of biopower, the most popular theoretical frame through which biometric security is currently being viewed.
\end{abstract}

Keywords: biometric security; racialization; biopower; colonialism; Iraq

\section{Introduction}

Biopower is something of a leitmotif these days, a fashionable and yet elusive concept deployed as an exploratory tool in a great many fields. In surveillance studies, biopower offers a starting point from which to investigate human life as a site of problematization, an object of political thought and the subject of technological interventions. The contemporary rollout of biometric security presents, at first glance, a striking example of biopower in operation. These technologies and their associated databases are a part of a fast-growing security assemblage that rests upon and enables the remaking of socio-cultural realities. To take migration management as an example, Michel Agier (2009) documents the holding zones that are filling in and remaking the world's borders. He describes Roissy-Charles-de-Gaulle Airport as a site in which extra-territorial and legally exceptional persons await processing. Until recently, an adjacent hotel accommodated business people and travellers, except on the first floor, which was given over as a security vestibule called 'ZAPI 2'. In one place, to paraphrase Elizabeth Bowen, different worlds lay alongside one another but did not touch. Agier's example calls attention to the contexts into which biometrics are being folded, technologies that are enabling the speed-up of mobility for some and the immobilization of others, technologies that seem imbricated with processes of racialization. But what, precisely, are the relationships between biometric technologies and racialization? And, in what ways might biopower be used as a tool with which to investigate those relationships?

\footnotetext{
*Email: Mark.H.Maguire@nuim.ie 
A variety of commentators have sought to go behind the representation of biometrics as value-free and scientific modes of identification. Instead, researchers argue that 'race' is often encoded in the systems themselves, and processes of racialization are a necessary condition for their function as a means to sort, categorize, grant access or exclude. However, much of this scholarship stops short upon finding evidence of racial thinking in design or deployment. In contrast, here I wish to pay specific attention to fingerprinting and face recognition and unpick specific cases in which processes of racialization are evident. This article argues that biometric security, historically and in the present, involves the securitization of individual identity and thus links the individual human body to configurations of population (see Sekula, 1986). Generally, therefore, new security technologies require the categorization of types within populations, from suspicious categories of persons to 'races'. Biometric security also involves, as the name implies, the measurement of human life itself. While it may seem obvious to theoretically approach this topic using the Foucauldian concept of biopower, care is needed to resist using biopower as an all-encompassing, totalizing concept that is capable of explaining everything (see Rabinow \& Rose, 2006, p. 198). Therefore, I wish to unpick the ways in which the securitization of identity folds into efforts to manage populations, incorporate abnormal and risky categories of persons, and allow for the maximization of forces within the calculations of governing. While this article is in part an effort to survey the ways in which biometric security is connected with process of racialization, I am also interested in the specific ways in which life is available within discourses of security. I examine contemporary and past examples of biometric security and their relationships to racialization, but I also include a discussion of emergent areas within the field in which life itself becomes the object of securitization. This article concludes with reflections on the concept of biopower.

\section{From bleeding edge to cutting edge}

Biometric security technologies use the information presented by the human body to establish and verify individual identity, whether by using characteristics such as the fingerprint, face or iris, or by means of bio-behavioural metrics such as gait, heart rhythm, voice or handwriting. In many parts of the world biometrics are associated in the popular imagination with criminal policing and this has occluded their historical emergence in civil and colonial administration. However, especially since 11 September 2001, these technologies have received considerable public attention, and extraordinary levels of public and private investment. Great attention has been paid to the areas of international travel and migration management, and deployments are often preceded by claims that such measures are a necessary weapon in so-called homeland security. It is also important to note that the biometrics industry is a global one, and much can be learned by attending to important developments outside of the Western world. A series of recent industry reports identify a shift in market and revenue growth away from Europe and North America towards South and Central America, the Asia-Pacific Region and the Middle East and North Africa (see Acuity, 2009; RNCOS, 2009). Many Western companies now operate as part of global consortia with various local partners, and regions such as the Middle East, where biometric security has been greeted with high levels of public acceptance, are regarded as testing grounds for technologies that will also become available other 
parts of the global market. Perhaps one of the most fascinating security laboratories is Iraq.

Journalist David Axe describes how in the early stages of the US invasion of Iraq the military 'lacked the tools' to carryout basic population management duties. He gives the example of the 4th Infantry Division, stationed in Northern Iraq in 2006:

\begin{abstract}
Army intelligence had provided them with a list including names, descriptions and in some cases outdated photos of known bad guys. The soldiers carried fuzzy colour copies of the list in their pockets and compared every passer-by to the descriptions. But the photos [were] too grainy and the descriptions too vague: pretty much every Iraqi man has a moustache, black hair and brown eyes. As for names? Besides sharing a small number of popular surnames, Iraqis have a habit of tacking their fathers and grandfathers name onto their own or even going by nicknames that dont [sic] match their photo IDs at all, assuming they even have photo IDs. There was just no way for the American soldiers to reliably know if they had happened to ensnare a bad guy in their net. (Axe, 2007, p. 1)
\end{abstract}

Biometric security provided the occupying forces with an advanced means to sift and control populations and engage in a series of calculations important for security and for the normal, day-to-day functioning of government. The key technology deployed was the Biometrics Automated Toolset (BAT). A recent article by Michael Neylon from the US Department of Defence's Biometrics Taskforce describes the everyday routines of Biometric Enrollers in Iraq:

\begin{abstract}
We start the process by vetting each person through the Biometrics Automated Toolset (BAT) ... There, each LCN [Local National] or TCN [Third Country National] is met by one of three enrollers. We get their paperwork and their form of ID and start the process of enrollment. First, we enter all the demographic information on each person; this usually consists of details such as one's height, weight, age, marital status, job position, etc. Then we collect their biometrics. In this phase, we collect all their fingerprints, iris scans, and six photos, all to FBI standards. Once all of these steps have been conducted, we submit the information back state-side to run it through criminal databases. This ensures that the people can be trusted and that they are who they claim to be. (Neylon, 2009)
\end{abstract}

BAT is essentially a multimodal biometric system that images characteristics from the fingerprint, iris and face and enrols, identifies and tracks individuals (using geospatial data), together with storing dossiers on especially suspect persons. BAT includes biometric readers, camera equipment, a robust laptop, server and hard drive. It also includes Handheld Interagency Identity Detection Equipment (HIIDE), portable devices roughly the size of a large camera that scan all three biometrics and remotely link with the Defence Department's Automated Biometric Information System database. According to the US Department of Defence Biometric Taskforce, next generation Automated Biometric Identification Systems (ABIS) will enable four distinct biometric modalities to be matched within a database representing over three million individuals with verification and even identification being returned in under 10 minutes.

A biometric industry representative discussed the HIIDE devices with me at a convention in 2008 and was at pains to point out that biometrics could not be understood as simply involving machines for reading the body; rather, biometric security involved, '[j] oined up systems and joined up thinking'. In conflict situations 
such as Iraq and Afghanistan, biometric security is a key tactic within broader strategic efforts to know populations and cannot be analytically separated from other interventions. As Roberto J. Gonzáles has shown, 'non-lethal' counterinsurgency strategy in Iraq and Afghanistan has for the past few years included a reinvigoration of the notion of 'tribe', often drawing on long discredited anthropological approaches, within 'sustainable security architecture' (Gonzáles, 2009, p. 18). And the widely commented upon US Army Human Terrain System is yet another example of a technique for population management that is embedded in a broader strategic framework, most directly the doctrine of counterinsurgency (COIN) which pushes for 'identity dominance'.

The example of biometrics at war is a useful one: it calls our attention to the scale and extent of the revolution in biometric technological advancement, the operational uses of (belatedly) 'joined up' systems, and the necessity to examine biometrics in the contexts of broader governmental efforts. However, even in tense situations such as theatres of war, the specific relationships between biometrics and racialization are often difficult to unpick, whilst rather old-fashioned notions of 'race' are frequently apparent in the less technical forms of knowledge such as the Human Terrain System. Consequently, in an insightful article that is critical of the uses of biometrics in Iraq, Andrew R. Horn states, 'Biometric technologies bear no relationship to more traditional notions of identity based on race, religion, or tribal bonds, and may seem a uniquely American or Western means of identification' (Horn, 2008, p. 8). Is this, indeed, the case? The task of examining the specifics of the relationships between biometrics, biopower and racialization must begin with the origins of the technologies. Here, I will discuss two forms of biometrics available in contemporary technology such as HIIDE equipment: fingerprinting and face recognition.

\section{A weapon of penetrating certainty}

William Herschel's The origin of fingerprinting (1916), written just prior to his death, looks back over his career as an imperial administrator and his contribution to the development of fingerprinting in colonial India. He includes the following description of the genesis moment in 1858 when he demanded a local contractor, Rajyadhar Konai, sign an agreement augmented with his hand print:

I was only wishing to frighten Konai out of all thought of repudiating his signature hereafter. He, of course, had never dreamt of such an attestation, but fell in readily enough. I dabbed his palm and fingers over with the home-made oil-ink used for my official seal, and pressed the whole hand on the back of the contract, and we studied it together, with a good deal of chaff about palmistry, comparing his palm with mine on another impression... One of these contracts I gave to Sir Francis (then Mr.) Galton... The very possibility of such a 'sanction' (to use a technical expression) to the use of a finger-print did not dawn upon me till after long experience, and even then it became no more than a personal conviction for many years more. (Herschel, 1916, p. 9)

Here, Herschel marks off his contribution as being that of an experimenting amateur capable of sanctioning useful knowledge. Upon being appointed Magistrate for the Hoogley District in 1877, he oversaw the Department of Registration, the courts and the jails and was quick to make use of fingerprinting, especially to combat fraud in pension claims, but also the hiring of prisoners and the faking of deaths. In 1877, 
Herschel wrote to the Inspector of Jails and the Registrar-General, and his comments on fingerprinting for criminal administration are striking:

Here is the means of verifying the identity of everyman in jail with the man sentenced by the court, at any moment day or night. Call the number up and make him sign. If it is he, it is he; if not, he is exposed on the spot. Is No. 1302 really dead, and is that his corpse or a sham one? The corpse has two fingers that will answer that question at once. Is this man brought into jail the real Simon Pure sentenced by the magistrate? The signmanual... is there to testify. (Herschel, 1916, p. 24)

Instead of a world filled with persons indistinguishable to the imperial gaze, Herschel's sign-manuals allowed individual identity verification to enter into governmental calculation (see also Caplan \& Torpey, 2001). Undoubtedly, his experiments must be situated in a thoroughly racialized world, but in many ways Herschel sought to go beyond 'race': for him, truly useful knowledge involved individual identities.

Simon Cole (2001) takes the example of the Criminal Tribes Act, 1871 as a way through which to understand how 'race' and security intersected in colonial India. For example, the jurist James Fitzjames Stephens categorized professional criminals as 'a tribe whose ancestors were criminals from time immemorial, who are themselves destined by the usage of caste to commit crime, and whose descendants will be offenders against the law, until the whole tribe is exterminated or accounted for' (as cited in Cole, 2001, p. 7). Cole further cites the extraordinary descriptions of such 'tribes': the criminal habits of the Rajwars, for example, included their being 'neglected, half-starved, and utterly degraded' (p. 68). But it is the latter part of Stephens's comments on criminal tribes that resonate most powerfully. The hereditary characteristics of 'race' marked them off as different, impossible to assimilate into imperial order, and thus marked them out for possible extermination. The securitization of identity, however, by means of which they could be 'accounted for', offered a form of incorporation that cannot be detached from racialization.

What, then, is the relationship between Herschel's experiments in fingerprinting and 'race'? It seems logical to simply state that racialization was one of the conditions for the possibility of fingerprinting, which was itself a mechanism for capturing the individual within broader efforts to map, know and govern colonial populations. However, it is also possible to argue that there is a deeper set of relationships between calculation, individual identity and 'race'. Herschel's experiments in fingerprinting were returned to Europe and to the scientific gaze of Darwin's cousin Francis Galton, as were Herschel's own prints, which would stand as an example of the persistency of patterns throughout the life of an individual.

For Galton, the core question in the science of fingerprinting was whether it could be used to distinguish a man from his fellows, and not just on the level of the individual. From the 1880s onwards Galton examined the prints of different English classes, Welsh from the remotest districts, Jewish schoolchildren, Africans from the territories of the Royal Niger Company, and Basques. In Finger Prints (1892) he notes that the differences between 'races' are generally not larger than those between groups within 'races'. Students in science could not be distinguished from 'the lowest idiots in the London district' (1892, p. 19). Jewish examples showed particular whorled patterns, and Galton held out hope that very remote populations might in 
future be found to have 'a more monkey-like pattern' (1892, p. 18). He was especially disappointed to note that there were no specifically 'Negro' patterns:

The impressions from Negros betray the general clumsiness of their fingers, but their patterns are not, so far as I can find, different from those of others ... Still, whether it be from pure fancy on my part, or from the way in which they were printed, or from some real particularity, the general aspect of the Negro print strikes me as characteristic ... they give an idea of greater simplicity, due to causes that I have not yet succeeded in submitting to the test of measurement. (Galton, 1892, pp. 195-196)

Though he could find no trace of temperament or 'race' in the arches, loops or whorls of the papillary ridges, Galton was sure that such traces would eventually be found. As late as 1903, he embarked on massive drive to collect new samples, but, again, without success. Paul Rabinow's essay, 'Galton's Regret' concludes a section on the polymath's efforts with fingerprints and 'race' by saying that his 'regret remains' (Rabinow, 1992, p. 115; see also Cohen, 1994, pp. 343-347). However, as Simon Cole has recently shown, the correlation between 'race' and fingerprints was pushed further by Galton's contemporaries and his students. Writing in 1920, Ethel M. Elderton noted that until the end of his life Galton clung onto the hope that a quantitative measurement applicable to any type would be found. Elderton's own research suggested that there was at least some evidence for arguing that inheritance could be found in fingerprints (Elderton, 1920). Even earlier, the Zoologist Harris Hawthorne Wilder envisaged the systematic use of fingerprints, palm and sole prints for the 'official identification of Chinese, negroes, and other races, the features of which, at least to the Caucasian eye, offer hardly sufficient individuality to be at all times trustworthy' (Wilder, 1902, pp. 439-440; see also Cole, 2007, p. 247). With Inez Whipple, Wilder went on to develop an evolutionary hierarchy which separated European and Asian fingerprint patterns. More recently, in 1982, Lin, Liu, Osterburg and Nicol provided hereditary evidence of fingerprint similarities in samples of twins.

In both the colonial context of its birth and in its uses in criminal investigation especially in the Western World, fingerprinting offered a seemingly value free, a-cultural, and purely scientific method of individual identity verification. But the haunting presence of 'race' has always threatened to reappear in the loops, arches and whorls. And, outside of the laboratory fingerprinting offered a way to govern without evoking 'race' but did not do away with it. To again quote Simon Cole:

Fingerprinting seems 'race neutral' because it averts its gaze; it looks only at the detailed level of papillary ridges... Fingerprinting, with its focus on the minute details of skin, could coexist with racial distinctions that were crude and arbitrary... The preservation of race, despite the development of a purportedly individualized identification technology, must be viewed not merely as an administrative convenience, but rather as being bound up with an entire culture and operationalization of institutional and individual racism. (Cole, 2007, pp. 258-259)

\section{'Race' and the face}

In 1888 Francis Galton brought together a number of influences to anticipate, yet again, contemporary biometric security. Throughout the late nineteenth century, Galton searched obsessively for something both within the body and marked upon it: 'hereditary resemblances and types of features' (Galton, 1888a, p. 174). Galton's initial 
foray into this topic occurred in the 1870s and 1880s with his efforts in composite portraiture. But by the late $1880 \mathrm{~s}$, conterminous with his work on fingerprint classification, he began working on personal identification of faces. At the same time, facial characteristics, among other anthropometric measurements, were being used in the French criminal identification process pioneered by Alphonse Bertillon, and Galton situates his work away from this method, which he believed to be scientifically unsound but 'effective in action' (Galton, 1888a, p. 174). Galton's 1888 paper, 'Personal Identification and Description', is striking for not just bringing these influences together but also for the extraordinary insights therein. It begins by thinking about general 'grades of unlikeness', before pushing towards the idea of developing 'a standard collection of contours' from which to identify facial profiles. Galton proposed using his double prism photographic visualizing technology to identify measurable differences in facial profiles which would then be classified using a complex mechanical selector instrument, which he had developed. More extraordinary still, the second part to this paper opens by identifying the possibilities of classification for individual identity by focusing on '[t]he markings in the iris of the eye' and the 'bifurcations and interlacements of the superficial veins' (Galton, 1888b, p. 201).

In a paper in Nature in 1910, Galton returned to the topic. If the lasting impression given by his early work on face recognition is that of the extraordinary fertility of his mind and the prescience of his suggestions, this later essay is even more striking for its ability to anticipate the contemporary. It begins with the suggestion that there is an innate mechanism for identifying, found among 'children or savages', which stresses several cardinal points, including, for example, the tip of the nose, which may be located on an x-y axis (Galton, 1910, p. 127). When elaborated on from this simple basis, Galton hoped that the facial profile would show racial and family characteristics useful for eugenic records - likeness could thus be expressed, or 'lexiconised' as word-like formulae convenient for telegraphy. The importance of this is that the facial profile could become the secondary means of identification supplementing fingerprint-based identification. Thus, 'A refugee criminal could easily be outstripped by his portrait, sufficiently like him to justify, in connection with corroborative evidence, his being placed for a while under police observation' (p. 127). But the entire system was only foreshadowing what was to come: Galton ends with a description of the level of exactitude required for the next stage in the order of accuracy: the face as dots connected by lines, more or less curved, sufficient to describe a face accurately in code.

In the early twentieth century, Francis Galton, father of eugenics, anticipated many of the basic features of contemporary biometric face recognition systems. Firstly, Galton anticipated the basic statistical and technological tools required. Secondly, he understood, as evidenced by his attention to lexiconizing human characteristics, that recognition technologies should be embedded in security systems. Thirdly, for Galton biometric identification was not merely a weapon of penetrating certainty but rather an emergent science deeply imbricated with evolutionary (and racial) theory.

\section{The contemporary face of biometrics}

While fingerprinting has a long history, developing first in civil applications in the colonial world, and in policing and immigration control in countries as diverse as the 
UK, Argentina and South Africa, face recognition still appears to be new, close to science fiction. Looking back, Francis Galton's early contribution appears to be a paradigm lost, and nearly half a century would pass before further steps were taken. During the 1960s in Palo Alto, AI pioneers W.W. Bledsoe, Helen Chan and Charles Bisson began work on the US intelligence-funded 'Man-Machine' project. They attempted to select facial coordinates such as the centre of the pupils from mug shots and correct for noise, such as tilt or lighting, enrol them into a computer database and then retrieve close distance matches. Even in these early experiments, the idea of using some three-dimensional techniques began to emerge. Bledsoe, not unlike Francis Galton, was a scientist with an extraordinary set of contributions, from genetic algorithms to dreaming of 'a special kind of computer, which had eyes and ears and arms and legs, in addition to its "brain"” (Bledsoe, 1986, p. 57), and recognition was just one way to simultaneously explore what the brain does and what computing technology could do just as well if not better.

Work begun during the 'Man-Machine' project progressed in the 1970s with the first semi-automated recognition systems being trialled, but it wasn't until the 1980s that the techniques took on a more familiar aspect with the development of the Eigenface technique based on principle component analysis (PCA); and PCA along with Linear Discriminant Analysis and Elastic Bunch Graph Matching are the corner stones of the techniques used today. Current face recognition technology generally operates by spatially and geometrically distinguishing features (attributes) in terms of their location and spatial relationship to one another, and systems often include analysis of the texture of the skin in 2D, 3D and infrared scans. The information is extracted as a digital template, smaller than the original scan, which is then used for comparison; however, the raw image is stored but not necessarily the template.

In practical displays and showcase events at biometrics conventions, face recognition technology is usually guaranteed to draw a crowd. Many companies will allow delegates and potential clients to quickly enrol in their system and then have them pass a surveillance camera and be authenticated by the system. One can watch on a screen as one's face is identified from among the crowd. Many technical experts, however, remain sceptical about face recognition. While the use of such technologies is recognised as reasonable for the purposes of authenticating identities already enrolled in databases and imaged in controlled environments, the idea that individuals may be identified in moving crowds with a reasonable degree of accuracy is greeted with raised eyebrows. Moreover, few would recommend being reliant on any one biometric, especially in secure environments. Nonetheless, face recognition is at the vanguard of biometrics research and development for several reasons. Firstly, it rests upon the history of photography and is thus acceptable to the public whilst offering existing archives of face images. Secondly, despite problems arising from contexts where veiling is common, it is regarded as non-intrusive and contact-less. And, finally, cutting edge systems hold out the promise of allowing for security authentication and identification without stopping people moving (Introna \& Wood, 2004).

The variability of the human face, together with issues such as rotation, makeup and lighting, present significant challenges to performance, and false acceptance (FAR) and false rejection rates (FRR) remain significantly higher for face recognition than for biometrics such as the fingerprint or iris. This has resulted in attention to $3 \mathrm{D}$ recognition, though those techniques require proximity to the (often 
very expensive) imaging devices and, with some systems, momentary stillness. Recent research has emphasised the value of using 3D Morphable Modelling to recover a three-dimensional model of the face from a 2D image. Moreover, 2D images are measurements of face geometry, albedo and skin pigmentation, and many scholars argue that biometric face recognition should be confined to intrinsic characteristics only. Added to this, 2D images are essentially dead, and current thinking is pushing for the capture of liveliness or 'proof of life' to prevent spoofing the system. Emergent 3D systems now operate by using scanners and cameras to generate a cloud of points, a texture map and often a mesh, which together work to produce a rather eerie image. And, within these systems, ethnicity or 'race' plays an interesting role.

The US National Science and Technology Council's (NSTC) briefing papers on biometrics openly states, 'The image data from a face recognition system may allude to the individual's ethnicity' (National Science and Technology Council [NSTC], 2006, p. 14). In a recent essay, Shoshana Magnet challenges the perspective that biometrics offer 'mechanical objectivity' and 'race'-neutrality. She argues that biometrics technologies are 'unable to distinguish the individual bodies of people of colour' (Magnet, 2009, pp. 370-371). This line of thinking is taken up further by Simone Browne (2009) who argues that Failure to Enrol (FTE) rates for very darkskinned users, and the use of specific facial characteristics, demonstrates a technological privileging of 'whiteness' through a form of 'race'-less racism (see also Pugliese, 2005). Thus, Joseph Pugliese describes biometric face recognition systems as 'infrastructurally calibrated to whiteness' (2007, p. 107 [original emphasis]).

These critical evaluations take as their starting point the notion that technologies are never a-cultural or value free, and they seek to disclose the ways in which design encodes basic cultural and societal understandings of the world. Therefore, to digitally discriminate between two individuals using biometrics is to deploy an already encoded eye that operates off and reifies social categories. However, the authors cited above make a number of assumptions that require consideration. Firstly, they assume that the biometric industry may be understood as essentially a Western world one, exporting technology, design and, thus, 'whiteness' to other parts of the world. In fact, the biometrics industry is becoming an evermore global one, and developments in especially Asia and the Middle East are often significantly ahead in biometric design and in deployment in the West. Secondly, these studies assume that 'race' or ethnicity are always understood as such by designers - in fact, skin pigmentation and variations in face geometry and characteristics are understood in the mainstream literature not in sociological ways but, rather, as technical obstacles cast occasionally in sociological terms.

Fingerprinting became an accepted form of useful technical knowledge, understood as value free and as a way through which to go behind the veil of broader, less useful and much more problematic categorizations of individuals. But the history of fingerprinting also includes the hidden connections between ostensibly neutral fingerprinting technology and extrinsic processes through which suspect populations are known and policed. Yet another part of that history charts the movement away from scientific studies of the connections between 'race' and fingerprints. However, characteristics of population understood as 'racial' have remained intrinsic to the biometric data of the papillary ridges. What of face recognition, then? Recently, Namdakumar, Ross and Jain (2008) outlined the ways in which multi-biometric 
systems make use of social data. In their study, they distinguish between intrinsic ancillary information, i.e. that data which denotes individual identity but also the quality of an image or 'noise', and extrinsic information from sources other than the biometric sample used to verify identity. It is useful to reflect on the idea that within the intrinsic ancillary domain that which is not adding to authentication or identification is degrading quality, i.e. a system that is 'infrastructurally calibrated to whiteness' (Pugliese, 2007, p. 107 [original emphasis]) would be, simply, faulty. However, extrinsic information is an entirely different matter. Such information may involve the addition of 'soft biometrics', also known as meta-data or biographic data - gender, ethnicity (often denoting 'race'), height - to enable fast matching in multimodal biometric systems wherein the quality of the 'hard' biometrics, such as the face, results in increased processing time delays and costs. In comparison, soft biometrics are data light and significantly reduce FAR and FRR rates.

The literature on soft biometrics, strikingly, draws on the work of nineteenthcentury Parisian detective Alphonse Bertillon's system of anthropometric classification and coding, which was used to identify recidivists and augmented the science of anthropometry with physical descriptions. Soft biometric trait-based systems resurfaced in recent years as a means to identify welfare recipients and research participants without stigmatizing them by subjecting them to conclusive identification methods such as fingerprinting (see Heckathorn, Broadhead \& Sergeyev, 2001). Extrinsic information from 'soft biometrics' may include gender, ethnicity or 'race', height, weight or accent, for example, but may also include scars and tattoos. Soft biometrics modules have already been used in real-time automatic extraction systems as a pre-identification module in first-stage processing. Soft biometrics are used to ameliorate current technical failings within biometric systems, allow for speed of processing and human mobility, and, perhaps more than anything, they add a rather old-fashioned plaster to contemporary biometrics industry problems. Soft biometrics do not simply, encode 'race' at the design stage, nor are we speaking of biometric systems resting alongside racializing systems for governing populations; rather soft biometrics seek out 'race', producing and reifying it in order to maintain the industrial pace of the biometrics business.

The above discussion of face recognition indicates the mutability of 'race'. We can speak of processes of racialization into which biometric security is folded, histories in which 'race' was the epistemological indicator by means of which the data presented by the human body was perceived and understood, and contemporary technical challenges which are met with racialized solutions as if little has changed since the nineteenth century. Therefore, the relationships between 'race' and biometrics are unstable and emergent. Moreover, while one may read a complex relationship between biometric securitization and racialization stretching back over a century, it is important to note that many of the major developments arose around the work of polymath scientists such as Francis Galton and W.W. Bledsoe. While each individual was a product of their own cultural and historical context, they shared an uncommon ability to stand outside of scientific paradigms and challenge the ways in which life could be seen, understood, replicated and identified. This, I argue, is crucial to understanding the relationships between biometric security and racialization: the history of biometric security speaks of the complex ways in which the characteristics of human beings and their collectivities have become the object of forms of knowledge, regimes of authority and specific interventions (see Rabinow \& Rose 
2006, p. 197). The final part of this article is a survey of recent developments in face recognition-based biometric security wherein I argue that life is being fore-grounded in striking ways. I use this final section as the basis from which to examine the implications for racialization and the concept of biopower.

\section{Measuring life}

Within ongoing debates among computer scientists and engineers there is little disagreement that the future will be marked by multimodal and interoperable systems sold to a broad governmental market hungry for every advance that promises to see the body in new ways. The goal is to ensure speed and circulation while sifting for 'bad guys'. Many are watching for developments in sensor capabilities and in market contexts such as surveillance. Among the growing areas of research and development one may find multi-spectral face recognition; and many systems now deploy thermal infrared technology to image the heat emitted from an individual's face. Concerns have been raised over the use of these technologies as they have a medical diagnostic capability - like retinal scanning, by way of another example, which can indicate symptoms of cancer and diabetes. However, perhaps the more interesting area marked out for future growth is that of the integration of affective computing with surveillance technology. It has long been recognised that in order to communicate with humans effectively, computers should be capable of recognizing emotions. It is a small step from there to imagine a world in which intelligent surveillance systems are capable of recognizing individual identities together with individual expressions of human emotions.

The potential synthesis between affective computing and surveillance technology rests upon the considerable contribution of psychologist and consultant Paul Ekman (see also Gray, 2003). During his impressive career, Ekman drew together Darwinian insights and the philosophical work of Silvan Tomkins on the nine human affects that are held to be biologically-based. Ekman also developed the Facial Action Coding System (FACS) during the 1970s - a taxonomy of human facial expressions. His work is widely cited in law enforcement and he remains a high-profile consultant. However, Ekman is rather sceptical about the automation of his system, and he recently came out against a major US Department of Homeland Security and Draper Laboratory project that aims to trial facial image and expression recognition for border crossings, the 'Future Attribute Screening Technology', which may be able to measure heart rhythm and facial expression variations. While this technology remains embryonic, it is interesting to mine into the issue of just what kind of human is being measured in these systems.

For Darwin, the original proponent of the hypothesis that there are underlying and universal human emotions, 'race' held an oddly descriptive value. For example, he concludes The Expression of the Emotions in Man and Animals (1872) by noting that comparative data, though sparse and biased, indicated similarity across cultures in terms of 'true, innate or instinctive emotional expression', thus indicating, '[T]he several races being descended from a single parent-stock, which must have been almost completely human in structure, and to a large extent in mind, before the period at which the races diverged from each other' (Darwin, 1872, p. 316). Darwin showed a desire to see Man without allowing 'races' to obscure the view. Universality mattered to Darwin because of evolution, and this stands out in stark contrast to his 
cousin and champion Francis Galton. In the period up to World War II, however, it was state racism and its 'sciences' such as eugenics that held sway. Little wonder then that for a generation of Boasian anthropologists 'human nature' became a battlefield upon which evidence of the role of socialization and culture (sometimes narrowly understood) was used to gain ground. Looking back on her career in the early 1970s, Margaret Mead described being compelled to focus on the malleability of human nature and leave to one side analysis of the universal until 'less troubled times'. And, for Ekman it is that which is universal that has consistently fascinated him: emotional expressions that are 'the same regardless of age, race, culture, sex, or education ... We are biosocial creatures...' (Ekman, 2006).

As we trace the history and contemporary uses of biometric security, a complex story emerges. The story is one of remarkable scientific minds, from Francis Galton's obsessive search for 'race' to W.W. Bledsoe's Man-Machine and Paul Ekman's efforts to understand the universal micro-facial expressions of biosocial creatures. Each of these pioneers confronted the challenge of measuring life in particular ways. From the late nineteenth century onwards, 'race' appears in different and mutable forms, foregrounded by Galton, largely set aside by Ekman. But the history of biometric security is also a story of useful knowledge and practical interventions on the ground, from administrators in colonial India to military personnel in contemporary theatres of war. Those working on the practical applications of biometrics imagine and image human bodies at a different level. The human body is understood as unique, therefore no two fingerprints are (or have been proven to be) alike, and at that same time is assumed to be generic, therefore everyone should have recognizable characteristics. But the biological body is not a straightforward password. From design to user experience the body is coupled with its social form, and socio-cultural ways of knowing the body are designed in. As biometric security is rolled out to tackle issues of migration control, counter-terrorism and insurgency and access to welfare benefits and spaces, the specific connections between biometrics and racialization need to be teased out. But biometrics also allow for a critical engagement with 'race' and racialization, especially as new forms of racism are enabled by biometric security, but also because the history of biometrics shows an inherent mutability in the notion of 'race'. Paul Gilroy has argued that the racialized body represents a 'moment in the transmission of code and information' (Gilroy, 2000, p. 36), but leaving to one side his hope that new technologies will herald a post-'race' humanism, the great value of his comment lies in his attention to 'race' and the racialized body as a figure of power-knowledge-space.

\section{Conclusions}

Much of the contemporary scholarship on biometric security references the Foucauldian concept of biopower (see Lyon, 2008; Epstein, 2007). But what exactly may be learned by using this concept as a tool for investigating biometric security and racialization? To conclude this article I wish set out an answer to this question by situating Foucault's ideas on biopower alongside a summary of the history of biometric security and some of the trends available in the contemporary moment.

Michel Foucault intended to devote an entire volume of the History of Sexuality to biopower, but his early death left the project unfinished. Until recently, the final 
evocative chapter of the History of Sexuality, vol. 1, Right of Death and Power over Life (1976/1990), offered one of the only obvious access routes to his ideas on biopower. Therein, Foucault traces two interlocking lines from the seventeenth century onwards: the development of an anatamo-politics of the human body, and the progressive regulation and control of the body as a figure of life itself, one life amid a living collective that required regulation and maximization - the biopolitics of population. Foucault directly connects his work on disciplinary power and biopower to racism and genocide, arguing that modern state racism and the horrors of genocide must be understood as ramifications of power being exercised at the level of life itself. The first volume of the History of Sexuality was completed as Foucault was delivering a series of lectures on war, 'race' and biopower at the Collège de France, published in English as Society must be Defended (2003). These lectures provide a rich insight into the formation of his thinking and indicate the central position he accorded to 'race'. In his lecture course, Foucault meticulously uncovers the counter-history of the wars between races (denoting 'people'). Modern racism is taken to rest upon this older history, but it gains specificity especially through its connections with evolutionism. Modern racism, linked with the rise of nations and nationalism, is a discourse on the purity of the 'race' and its defence against enemies, not a warrior's battle taken as an underlying condition of society but an evolutionary struggle to protect the 'race' itself (Foucault, 2003, p. 80). Society must be Defended does not imagine Nazism as the exemplar of biopolitics or argue that the defeat of fascism would spell the demise of biopolitical state racism; rather, Foucault is interested to unpick the ways in which 'race' relates to a form biopower that administers life, regulates the population, and engages in complex processes of calculation within and well beyond the state.

Biopower, then, is does not offer an all-encompassing and totalizing concept but rather a powerful tool with which to begin to investigate human life as a site of problematization, an object of political thought and the subject of technological interventions (see Rabinow \& Rose, 2006, p. 198). From this starting point, it is possible to get closer to understanding the how life was problematized in the late nineteenth century by scientists and administrators and the ways in which biometric security offered useful knowledge for the government of individuals and populations. Biometric technologies offered identity verification at the level of the individual in a world in which bodies and populations were configured by racial thought. While overt racial theory has largely disappeared from contemporary scientific projects in this field, a survey of biometrics in the contemporary moment shows the remarkable persistence of racialization in security discourse today. From the theatres of war in which biometrics are used to ensnare bad guys, to efforts to join up affective computing with surveillance technology, the concept of biopower provides a starting point from which to investigate the ways in which security assemblages are imbricated with processes of racialization, and investigate the ways in which seemingly post-racial science is also being folded into governmental calculations. Biopower involves statistics, profiles, a multitude of useful knowledge, monitoring, surveillance, and the ordering of space; birth and death rates - sciences concerned with biosocial creatures and technologies that seek to identify individuals both have as their object life itself. 


\section{Acknowledgements}

The author wishes to thank Mag. Katja Seidel for pointing out the importance of tracing the genealogy of biometrics and 'race'.

\section{References}

Acuity. (2009). The future of biometrics 2009, revised edition. Louisville, KY: Acuity Market Intelligence.

Agier, M. (2009). The camps of the twenty-first century: Corridors, security vestibules and borders of internal exile. Managing migration? The politics of truth and life itself. Irish Journal of Anthropology, 12(3, Special Issue), 62-73.

Axe, D. (2007, February 26). Gotcha! Ares: A defence technology blog. Retrieved May 15, 2010, from http://aviationweek.typepad.com/ares/2007/02/index.html

Bledsoe, W.W. (1986). I had a dream: AAAI Presidential Address, 19 August 1985. AI Magazine, 7, 57-61.

Browne, S. (2009). Digital epidermalization: Race, identity and biometrics. Critical Sociology, $36(1), 131-150$.

Caplan, J., \& Torpey, J. (Eds.) (2001). Documenting individual identity: The development of state practices in the modern world. Princeton, NJ: Princeton University Press.

Cohen, L. (1994). Whodunit? - violence and the myth of fingerprints: Comment on Harding. Configurations, 2(2), 343-347.

Cole, S.A. (2001). Suspect identities: A history of fingerprinting and criminal identification. Boston, MA: Harvard University Press.

Cole, S.A. (2007). Twins, Twain, Galton, and Gilman: Fingerprinting, individualization, brotherhood, and race in Pudd'nhead Wilson. Configurations, 15(3), 227-265.

Darwin, C. (1872). The expression of the emotions in man and animals. London: John Murray.

Eckman, P. (2006). Darwin and facial expression: A century of research in review. New York, NY: Malor Books.

Elderton, E.M. (1920). On the inheritance of the finger-print. Biometrika, 13, 57-91.

Epstein, C. (2007). Guilty bodies, productive bodies, destructive bodies: Crossing the biometric borders. International Political Sociology, 1, 149-164.

Foucault, M. (1990). The history of sexuality: An introduction, volume 1. London: Vintage. (Original work published 1976)

Foucault, M. (2003). 'Society must be defended', lectures at the College de France, 1975-1976. London: Allen Lane.

Galton, F. (1888a). Personal identification and description: I [the substance of a lecture given in the Royal Institution 25 May 1888]. Nature, 21 June, 173-177.

Galton, F. (1888b). Personal identification and description: II. Nature, 28 June, 201-202.

Galton, F. (1892). Finger prints. London: Macmillan.

Galton, F. (1910). Numeralized profiles for classification and recognition. Nature, 83 (31 March), 127-130.

Gilroy, P. (2000). Against race: Imagining political culture beyond the colour line. Cambridge, MA: Harvard University Press.

Gonzáles, R.J. (2009). Going 'tribal': Notes on pacification in the 21st century. Anthropology Today, 25(2), 15-19.

Gray, M. (2003). Urban surveillance and panopticism: Will we recognize the facial recognition society? Surveillance and Society, 1(3), 314-330.

Heckathorn, D.D., Broadhead, R.S., \& Sergeyev, B. (2001). A methodology for reducing respondent duplication and impersonation in samples of hidden populations. Journal of Drug Issues, 32(2), 543-564.

Herschel, W. (1916). The origin of fingerprinting. London: Oxford University Press.

Horn, A.R. (2008). The new legs race: Critical perspectives on biometrics in Iraq. Military Review, 88, 85-94.

Introna, L.D., \& Wood, D. (2004). Picturing algorithmic surveillance: The politics of facial recognition systems. Surveillance and Society, 2(2-3), 177-198. 
Lin, C.H., Liu, J.H., Osterburg, J.W., \& Nicol, J.D. (1982). Fingerprint comparison I: Similarity of fingerprints. Journal of Forensic Sciences, 27(2), 290-304.

Lyon, D. (2008). Biometrics, identification and surveillance. Bioethics, 22(9), 499-508.

Magnet, S. (2009). Using biometrics to re-visualize the Canada-US border. In I. Kerr, V. Steeves \& C. Lucock (Eds.), On the identity trail: Anonymity and authentication in a networked society (pp. 359-377). Oxford: Oxford University Press.

Nandakumar, K., Ross, A., \& Jain, A.K. (2008). Incorporating ancillary information in multibiometric systems. In A.K. Jain, P.J. Flynn \& A. Ross (Eds.), Handbook of biometrics (pp. 335-357). London \& New York, NY: Springer.

National Science and Technology Council. 2006. Biometrics Frequently Asked Questions. Retrieved May 28, 2012, from http://biometrics.gov/Documents/FAQ.pdf.

Neylon, M. (2009). Another day in paradise. The Biometric Scan, 5(2). Retrieved February 12, 2010, from http://www.biometrics.dod.mil/Newsletter/issues/2009/Apr/v5issue2_a4.html

Pugliese, J. (2005). In silico race and the heteronomy of biometric proxies: Biometrics in the context of civilian life, border security and counter-terrorism laws. The Australian Feminist Law Journal, 23, 1-32.

Pugliese, J. (2007). Biometrics, infrastructural whiteness and the zero degree of nonrepresentation. Boundary 2, 34(2), 105-133.

RNCOS. (2009). Global biometric forecast to 2012. Noida, India: RNCOS.

Rabinow, P. (1992). Galton's regret: Of types and individuals. In P.R. Billings (Ed.), DNA on trial: Genetic identification and criminal justice (pp. 5-17). New York, NY: Cold Spring Harbor Laboratory Press.

Rabinow, P., \& Rose, N. (2006). Biopower today. BioSocieties, 1, 195-217.

Sekula, A. (1986). The body and the archive. October, 39, 3-64.

Wilder, H.H. (1902). Palms and soles. American Journal of Anatomy, 1, 439-440. 